\title{
Pengelolaan Sistem Dusung Di Negeri Laha Kecamatan Telutih Kabupaten Maluku Tengah
}

\author{
Falen J. Sitaniapessy ${ }^{1}$, Marcus. J. Pattinama2 ${ }^{2}$ Juanita F. Sopamena ${ }^{3}$ \\ 1,2,3 Program Studi Agribisnis, Fakultas Pertanian, Universitas Pattimura Ambon \\ email:falensita02@gmail.com \\ Diterima: Mei 2021, Disetujui: Juni 2021, Diterbitkan: Juni 2021
}

\begin{abstract}
Abstrak
Penelitian ini bertujuan untuk menganalisis pengelolaan sisttemdusungdi Negri Laha Kecamatan Telutih Kabupaten Maluku Tengah.Penentuan sampel dilakukan secara sengaja (purposive sampling) dimana sampel yang diambil berdasarkan jumlah pemilik dusung. Data yang digunakan adalah data primer dan data sekunder. Data primer menggunakan metode wawancara secara langsung dengan responden, melakukan observasi atau pengamatan langsung dilapangan dan dokumentasi berupa setiap kegiatan yang akan dilakukan dilokasi penelitian.Sementara data sekunder dilakukan pada kantor atau instansi terkait guna mengumpulkan informasi yang lebih detail untuk menunjang data primer yang telah dikumpulkan. Hasil penelitian menunjukkan bahwa bahwa sistem pengelolaan dusung yang diterapkan masyarakat Negri Laha adalah sistem pengelolaan secara pribadi dan pengelolaan dusung secara mata rumah.Pengelolaan dusung yang dilakukan masyarakat Negri Laha lebih mendominasi pada sistem pengelolaan secara pribadi yaitu sebanyak 20 responden dan sistem pengelolaan secara mata rumah sebanyak 10 responden. Tahap pengelolaan dusung yang ada di Negri Laha dimulai dari persiapan lahan, penanaman, pemeliharaan, pemanenan sampai pasca panen.

Kata kunci:
\end{abstract}

Dusung; Pengelolaan, Sistem

\begin{abstract}
This study aims to analyze the management of the dusung system in NegriLaha, Telutih District, Central Maluku Regency. Determination of the sample is done intentionally (purposive sampling) wherein the sample taken is based on the number of dusung owners. The data used are primary data and secondary data. Primary data uses the method of direct interviews with respondents, making observations or direct observations in the field and documentation in the form of every activity that will be carried out at the research location. While secondary data is carried out at the relevant office or agency in order to collect more detailed information to support the primary data that has been collected. The results showed that the dusung management system applied by the Negri Laha community was a personal management system and dusung management in a household eye. The management of dusung which is carried out by the people of Negri Laha is more dominant in the personal management system, which is 20 respondents and the housing management system is 10 respondents. The stage of managing dusung in Laha Negri starts from land preparation, planting, maintenance, harvesting until post-harvest.
\end{abstract}

Keywords:

Dusung; Management, System

How to Cite: Falen J. Sitaniapessy, Marcus. J. Pattinama, Juanita F. Sopamena.(2021). Pengelolaan Sistem Dusung Di Negeri Laha Kecamatan Telutih Kabupaten Maluku Tengah. Jurnal Penelitian Agrisamudra. 8(1):1-9

DOI 10.33059/jpas.v8i1.3703 


\section{Pendahuluan}

Indonesia merupakan salah satu negara agraris. Sehingga sektor pertanian sangat penting dalam mendukung perekonomian negara sebagai penyedia sandang, pangan dan papan. Maluku merupakan provinsi kepulauan yang terletak di sebelah timur indonesia. Secara astronomis, wilayah maluku terletak antara 2030 ' -90 Lintang Selatan dan 1240 - 1360 Bujur Timur. Luas wilayah Provinsi Maluku secara keseluruhan adalah $581.376 \mathrm{~km} 2$, terdiri dari luas lautan $527.191 \mathrm{~km} 2$ dan luas daratan $54.185 \mathrm{~km} 2$. Yang berarti bahwa sekitar 90 persen wilayah Provinsi Maluku adalah lautan (BPS Maluku, 2018).

Provinsi maluku memiliki ciri khas yaitu topografi yang berbukit dan bergunung, terdiri dari gugusan pulau-pulau kecil dengan bentangan garis pantai yang panjang, kondisi iklim, potensi sumber daya alam, kondisi sosial ekonomi dan budaya masyarakat yang beragam dan kepekaan ekologi terhadap suatu perbedaan. Itu berarti pola pertanian yang di terapkan juga berbeda dengan wilayh lainnya.Pertanian di pulau-pulau kecil harus memiliki konsep pertanian yang berbeda yang di susun dalam suatu pembangunan pertanian secara terpadu dan berkelanjutan.Untuk itu salah satu teknik pemanfaatan lahan yang dapat berperan dalam menjaga kelestarian lingkungan alam ini adalah dengan sistem agroforestry.

Agroforestry merupakan sistem pertanian yang sudah dilakukan para petani sejak jaman dahulu dan di wariskan sampai sekarang ini dengan mengkombinasikan tanaman pertanian dan tanaman kehutanan. Agroforestri akan menekankan penggunaannya pada jenis-jenis pohon serba guna dan menentukan asosiasi antara jenis-jenis vegetasi yang ditanam.Dalam konteks agroforestri, pohon serbaguna mengandung pengertian semua pohon atau semak yang digunakan atau dikelola untuk lebih dari satu kegunaan produk atau jasa; yang penekanannya pada aspek ekonomis dan ekologis (Senoaji, G. 2012 dalam Amin dkk, 2016).

Seperti yang di katakan oleh (Pattinama,2014) Pengembangan komoditas pertanian tidak dapat dipisahkan dari pengembangan peradaban manusia. Jika ini semua tercapai maka kita telah menciptakan program kecukupan pangan bagi masyarakat yang hidup disekeliling sumberdaya alam yang melimpah. Sehubungan dengan semakin banyak bertambahnya jumlah penduduk dan peningkatan pemanfaatan lahan untuk bercocok tanam maka ketersediaan lahan semakin berkurang. Untuk itu pemanfaatan lahan haruslah dilakukan seoptimal mungkin.

Konsep wanatani merupakan salah satu bentuk usaha pelestarian sumber daya alam yang dapat meningkatkan produktifitas sumber daya hutan sekaligus meningkatkan pendapatan masyarakat. Konsep ini muncul sebagai suatu sistem untuk mengkombinasikan tanaman pertanian dengan tanaman kehutanan yang dapat mengurangi erosi dan mempertahankan kesuburan tanah (Oszaer, 1996).

Sebagai satu bentuk wanatani tradisional, dusung tidak hanya berperan penting dalam melestarikan sumber daya alam tetapi berperan juga sebagai penunjang sosial ekonomi masyarakat. Untuk itu di perlukan suatu sistem manajemen yang baik agar fungsi ekologi, dan sosial ekonomi dapat tercapai yang pada akhirnya kesejahteraan masyarakat pun dapat terwujud.Sistem pertanian tradisional dengan pola dusung ini 
terus dikembangkan dan dipraktekan oleh petani di Maluku sebagai suatu usaha untuk meningkatkan taraf hidup rumah tangganya, (Berhitu, 2007).

Untuk mengetahui sejauh mana pola manajemen dari dusung demi kesejahteraan masyarakat di Maluku Tengah, maka di lakukan penelitian pada Negri Laha Kecamatan Telutih Kabupaten Maluku Tengah sehingga diharapkan dapat memberikan data yang akurat dalam menunjang penelitian ini.

Kajian tentang dusung sudah banyak di lakukan di maluku tetapi pola manajemen dusung serta pemanfaatan dusung dari aspek lingkungan dan aspek sosial ekonomi masyarakat masih perlu dilihat lagi sehingga hal di atas mendorong penulis untuk melakukan suatu penelitian mengenai pola manajemen dusung di Negri Laha, kecamatan Telutih, Kabupaten Maluku Tengah.

\section{Metode Penelitian}

Penelitian ini dilakukan di Negri Laha Kecamatan Telutih Kabupaten Maluku Tengah, dimanamasyarakat di Negri Laha umumnyabermata pencaharian sebagai petani serta merupakan salah satu sumber pendapatan masyarakat dilokasi penelitian.

Sampel penelitian dipilih secara sengaja (purposive sampling) yaitu dimana sampel yang diambil berdasarkan jumlah pemilik dusung. Pengambilan sampel ini dilakukan dengan mendata jumlah keluarga atau penduduk yang merupakan pemilik dusung. Jumlahsampel yang diambilsebanyak 30 responden.

Data yang dikumpulkan dalam penelitian ini ada dua jenis data yaitu, data primer dan data sekunder. Data primer diperoleh langsung melalui wawancara dengan masyarakat atau responden, kemudian pengisian daftar pertanyaan (quesioner) dan observasi. Sementara data sekunder diperoleh secara langsung dari instansi terkait dimana data tersebut meliputi gambaran tentang keadaan geografis, keadaan sosial ekonomi masyarakat serta literatur lainnya (artikel, skripsi dan buku) yang menunjang atau berkaitan dengan penelitian ini.Dalam penelitian ini, analisis data yang gunakan adalah kualitatif deskriptif

\section{Hasil dan Pembahasan \\ Karakteristik Petani}

Karakteristik petani umumnya berkaitan dengan umur, tingkat pendidikan, pekerjaan, luas lahan. Umur terbagi atas 3 kategori yakni umur belum produktif, umur produktifdan kurang produktif. Umur belum produktif produktif yakni $0-14$ tahun, umur produktif yakni 15 - 55 tahun dan umur kurang produktif yakni diatas 55 tahun (BKKBN, 1998).

Pendidikan sangatlah penting untuk mengukur kesejahteraan masyarakat.Menurut Sedarmayanti (2003), melalui pendidikan seseorang dipersiapkan untuk memiliki bekal agar siap tahu, mengenal dan mengembangkan metode agar bisa memecahkan masalah yang akan dihadapi dalam kehidupan dikemudian hariPendidikan juga dilakukan untuk meningkatkan taraf hidup yang lebih baik. Yang di maskud dalam penelitian ini adalah pendidikan formal yang diperoleh responden dalam mengelola sistem dusung. 
Pekerjaan merupakan bagian yang sangat penting bagi manusia karena dengan bekerja manusia dapat menghasilkan barang dan jasa, sehingga segala kebutuhannya dapat terpenuhi. Selain itu, pekerjaan juga dapat diartikan sebagai suatu kebutuhan yang harus dilakukan terutama untuk menunjang kehidupannya dan kehidupan keluarga (Nursalam, 2003).

Hernanto(2007), membagi luas lahan menjadi tiga kategori, yaitu luas lahan sempit $<0,5$ hektar, luas lahan sedang 0,5 sampai 2,0 hektar, dan luas lahan luas $>2,0$ hektar. Luas lahan yang dimiliki sangat berpengaruh pada pendapatan, sehingga semakin luas sebuah lahan maka semakin besar pendapatan yang diterima oleh seorang petani. Berikut karakteristik responden di lokasi penelitian (Tabel 1).

Tabel 1. Karakteristikpetani

\begin{tabular}{|c|c|c|c|}
\hline Karakteristik Responden & Kategori & $\begin{array}{l}\text { Jumlah } \\
\text { (Orang) }\end{array}$ & $\begin{array}{l}\text { Persentasi } \\
(\%)\end{array}$ \\
\hline \multirow[t]{3}{*}{ Umur } & Produktif (15 - 55 Tahun) & 24 & 80,00 \\
\hline & $\begin{array}{c}\text { Kurang Produktif (> } 55 \\
\text { Tahun) }\end{array}$ & 6 & 20,00 \\
\hline & Total & 30 & 100,00 \\
\hline \multirow[t]{5}{*}{ Tingkat Pendidikan } & SD & 14 & 46,67 \\
\hline & SMP & 7 & 23,33 \\
\hline & SMA & 8 & 26,67 \\
\hline & S1 & 1 & 3,33 \\
\hline & Total & 30 & 100,00 \\
\hline \multirow[t]{3}{*}{ Pekerjaan } & Utama & 12 & 40,00 \\
\hline & Sampingan & 18 & 60,00 \\
\hline & Total & 30 & 100,00 \\
\hline \multirow[t]{4}{*}{ Luas lahan dusung (Ha) } & $<0,5$ & 11 & 36,67 \\
\hline & $0,5-2,0$ & 10 & 33,33 \\
\hline & $>0,5$ & 9 & 30,00 \\
\hline & Total & 30 & 100,00 \\
\hline
\end{tabular}

Tabel 1 menunjukkan bahwa terdapat perbedaan umur, tingkat pendidikan, pekerjaan, luas lahan. Hal ini berarti dalam melaksanakan usaha dusung, dari aspek fisik terdapat perbedaan curahan waktu kerja, dari aspek pendidikan akan terdapat perbedaan pola 
pikir yang berkaitan dengan strategi produksi maupun pemasaran. Demikian dari aspek luas lahan, dalam proses produksi tanaman yang ada dalam dusung juga akan terdapat perbedaan khususnya dalam hasil produksi, dalam hal ini petani yang memiliki luas lahan > dari 0,5 hektar memiliki pendapatan yang lebih tinggi dari petani yang memiliki luas lahan $<0,5$ hektar.

\section{Manajemen dusung di Negri Laha}

Ada beberapa bentuk sistem pengelolaan dusung yang sering dipakai masyarakat dalam mengelola dusung diantaranya Pengelolaan dusung secara pribadi, yaitu proses pengelolaan dusung yang diusahakan secara pribadi tanpa adanya campur tangan dari pihak lain.Pengelolaan dusung secara mata rumah (dati) yaitu, proses pengelolaan dusung atas dasar kesepakatan bersama, namun hanya dalam lingkup keluarga, atau marga tertentu.Pengelolaan dusung secara kelompok yaitu, proses pengelolaan dusung yang dilakukan secara berkelompok dalam kelompok tani maupun dusung milik gereja yang dikelola secara bersama-sama untuk kepentingan gereja.

Hasil penelitian menunjukkan bahwa sistem pengelolaan dusung yang diterapkan masyarakat Negri Laha adalah sistem pengelolaan secara pribadi dan pengelolaan dusung secara mata rumah.

Tabel 2. Sistem pengelolaan dusung

\begin{tabular}{lcc}
\hline \multicolumn{1}{c}{ Sistem Pengelolaan } & Jumlah Responden & Presentasi \% \\
\hline Pribadi & 20 & 66,67 \\
Mata Rumah & 10 & 33,33 \\
\hline Total & $\mathbf{3 0}$ & $\mathbf{1 0 0 , 0 0}$ \\
\hline
\end{tabular}

Tabel 2 menunjukkan bahwasistem pengelolaan dusung yang dilakukan masyarakat Negri Laha lebih mendominasi pada sistem pengelolaan secara pribadi yaitu sebanyak 20 responden dan sistem pengelolaan secara mata rumah sebanyak 10 responden. Pengelolaan dusung secara pribadi yaitu dusung tersebut sudah menjadi milik pribadi yang sudah diberikan atau diwariskan dari orang tua kepada mereka, sehingga mereka berhak atas dusung tersebut dan mengelola secara pribadi tanpa campur tangan dari keluarga maupun pihak lain karena telah dibagi sama besarnya.

Masyarakat Negri Laha lebih memilih mengelolah dusung secara pribadi dikarenakan sebagian besar masyarakat Negri Laha bermata pencaharian sebgai petani dan hasil yang didapat lebih banyak. Dari sistem pengelolaan dusung secara pribadi, masyarakat dapat memperoleh manfaat secara langsung, dimana mereka lebih mengetahui dusung yang mereka kelola dan hasil yang didapati lebih memuaskan karena tidak adanya sisten bagi hasil dengan orang lain.

Pengelolaan dusung secara Mata Rumah merupakan suatu pengelolaan dusung berdasarkan fam atau marga tertentu dimana dusung tersebut secara tuun temurun diwariskan kepada anak-anak mereka dan mereka yang berhka mengelola dusung 
tersebut secara bergiliran sesuai dengan kesepakatan yang dibuat dan dalam proses pengambilan hasil dusung ada aturan kapan akan diambil hasil dusung tersebut sesuai dengan waktu yang disepakati bersama oleh keluarga besar.

Sistim bagi hasil yang biasanya dilakukan masyarakat adalah setiap keluarga yang mengelola dusung tersebut berhak untuk menikmati hasil dusung tersebut dan tidak di bagi ke keluarga yang lain, karena keluarga yang lain juga akan mendapatakan kesempatan yang sama juga.

Sistem pengelolaan dusung secara kelompok yang dilakukan masyarakat Negri Laha adalah pengelolaan dusung secara bersama-sama seperti dusung milik gereja. Dusung milik gereja dikelolah oleh semua anggot jemaat secara bersama-sama tujuannya adalah untuk kepentingan gereja. Dimana dusung tersebut dimiliki bukan oleh suatu pewarisan melainkan di berikan hak seutuhnya kepada gereja. Hasil dari dusung gereja sepenuhnya akan diperuntukan kepada pengembangan gereja dan anggota jemaat. Jenis tanaman yang ada pada dusung gereja adalah kelapa, pala, dan cengkih.

Menurut Pattinama(2014), orang seram hidup menyatu dengan alam. Pengetahuan mengelolah alam diperoleh secara turun temurun dengan hanya mengandalakan deskripsi lisan. Masyarakat Negri Laha yang hidup selalu menyatu dengan alam sehingga banyak dari mereka yang menjadikan alam sebagai penunjang hidup. Pengetahuan tentang alam yang didapati dari cerita orang tatua secara turun temurun selalu di lakukan dan dpraktekan sampai sekarang ini.

Menurut Nair dalam Latue, (2018). Agroforestry adalah suatusistem penggunaan lahan yang berorientasi sosial dan ekologikal dengan mengkombinasikan tanaman pertanian dan tanaman kehutanan untuk mendapatkan total produksi secara berkelanjutan dari suatu unit lahan.Wattimena dan Papilaya (2005) mengatakan bahwa keragaman dalam fungsi sistem dusung menyebabkan terjadinya sinergi sementara komponen yang saling menguntunkan.Yaitu komponen tanaman dengan komponen tanaman maupun komponen tanaman dengan komponen hewan sehingga menciptakan kondisi yang menguntungkan diantara komponen dalam suatusistem agroforestry secara keseluruhan. Keunggulan dari agroforestry yaitu (a) pengolahan lahan yang lebih efektif dan efisien, (b) kesinambungan ekologi dan ekonomi tetap terjaga, (c) pendapatan dari praktik agroforestry sama atau lebih besar dari pada pendapatan di luar ag atau mengurangi roforestry (d) waktu panen bervariasi antara satu komoditas dengan komoditas lainnya (e) dapat menutupi kerugian akibat gagal panen salah produk agroforestry.Tahap Pengelolaan Dusung yang ada di Negri Laha antara lain:

\section{Persiapan Lahan}

Tahap perisiapan lahan yang dilakukan oleh masyarakat Negri Laha yaitu, masyarakat mempersiapkan lahan baru hanya untuk proses penanaman tanaman pangan karena untuk tanman tahunan, tanaman musiman, dan kayu kayuan sudah ada didalam dusung. Namun ada beberapa responden yang biasanya menanam tanaman tahunan yang baru untuk menggantikan tanaman yang tidak produktif contohnya kelapa. Tanaman pangan yang di tanam seperti singkong, pisang, kunyit, jahe, serai, dan tanaman pangan lainnya. Persispan lahan dilakukan dengan cara membersihan lahan 
dari semak belukar, ranting pohon dan rumput rumput yang di potong kemudian dikumpulkan dan dibakar. Setelah laha telah dibersihkan selanjutnya masyarakat mempersiapkan hal untuk penanaman seperti membuat bedengan untuk tanaman singkong, membuat kuming untuk tanaman talas, dan membuat lubang untuk tanaman pisang, serai dan jahe dan membuat lubang untuk menanam tanaman musiman yang baru untuk menggantikan tanaman yang tidak produktif.

\section{Penanaman}

Proses penanaman dimulai dengan menentukan areal/lokasi jenis tanaman yang akan ditanam, mengatur jarak tanam setiap komoditas khususnya tanaman pangan agar tidak terjadi penumpukan pada suatu lokasi. Untuk penanaman serai jahe dan kunyit masyarakat hanya membuat lubang sebesar anakan tanaman dan langsung di tanam di tanah tanpa melalui perantara seperti polibek tujuannya agar tanaman tersebut dapat tumbuh dengan subur dan rimbun karena tidak kekurangan air dan unsur hara dari tanah. Untuk penanaman singkong masyarakat membuat kolam dan langsung memasukan batang singkong kedalam tanah kemudian tanahnya di timbun membentuk bedengan satu per satu begitu halnya juga dengan pisang yaitu dibuat lubang dan tunas pisang di masukan kedalam lubang tersebut. Untuk tanaman musiman yaitu kelapa, masyarakat melakukan proses penanaman dengan cara membuat lubang sebesar tunas kelapa dan menanam tunas kelapa tersebut dengan jarak beberapa senti meter dari pohon kelapa yang sudah tidak produktif.

\section{Pemeliharaan}

Pemeliharaan tanaman yang dilakaukan masyarakat Negri Laha yaitu untuk tanaman musiman dan tahuanan dengan cara membersihkan lahan dengan cara pameri dengan tujuan untuk membersihakan lahan dari tanaman pengganggu seperti semak belukar, alang-alang, dan gulma dikarenakan tanaman pengganggu dapat mempengaruhi proses pertumbuhan tanaman tersebut. masyarakat juga memerlukan pemeliharaan yang ekstra dari organisme pengganggu tanaman seperti hama babi liar yang selalu masuk kedalam dusung masyarakat untuk merusak tanaman. Pemeliharaan yang dilakukan untuk mencegah hama babi yaitu dengan membuat jerat babi dan pagar sebagai pelinfung dari gangguan hama babi tersebut. Untuk tanaman pangan masyarakat memelihara dengan cari membersihkan tanaman dari rumput liar dan menyirami dengan air tanpa pemberian pupuk kimia.

\section{Pemanenan}

Tahap pemanenan yaitu proses pengambilan hasil dari dusung. Baik itu untuk tanman pangan, maupun tanaman musiman maupun tanaman tahunan. Untuk tanaman pangan tidak memerlukan tenaga kerja karena tidak sulit utuk memanen tanaman pangan. Sedangkan untuk tanaman musiaman, tanaman perkebunan, dan tanaman tahunan seperti kelapa, pala dan cengkih, Pemilik dusung terkadang memerlukan tenaga kerja untuk membantu memanen hasil dusung baik tenaga kerja dari dalam keluarga maupun tenaga kerja dari luar keluarga. Untuk tenaga kerja dari dalam keluarga pemilik dusung atau responden hanya menggunakan keluarga untuk membantu memanen hasil dusung yaitu anak mereka yang sudah beranjak dewasa 
untuk membantu. Sedangkan untuk tenaga kerja luar keluarga pemilik dusung atau responden biasanya memberikan upah kepada mereka untuk membantu memanen hasil dusung. Upah yang di berikan kepada tenaga kerja dari luar keluarga yaitu menggunakan sistem basgi hasil. Dimana jika tenaga kerja dari luar eluarga yang digunakan antara 2 sampi 4 orang maka sistem bagi hasil yang dilakukan yaitu. Semua hasil dusung yang sudah terkumpul akan dibagi 2 dengan tenaga kerja. Yaitu setengah untuk di bagi kepada 2 atau 4 orang pekerja sedangkan setengahnya lagi untuk pemilik dusung untuk komoditas tertentu.

\section{Pasca Panen}

Setelah masyarakat memanen hasil dusung, mereka kemudian menjualnya ke pedagang pengumpul ataupun ke pasar untuk memenuhi kebutuhan sandang, pangan dan papan serta pendidikan anak. Namun tidak semua hasil panen dijual karena sebagian lagi dipakai untuk konsumsi sehari-hari dan sebagian lagi seperti cengkih biasanya disimpan sampai harga dari cengkih mengalami kenaikan barulah cengkih tersebut di jual. Untuk komoditas kelapa dan pala langsung dijual karena kalau kelapa jika disimpan lebih dari satu hari akan terjadi penyusutan sampai 5 kilogram dalam satu karung. sehingga membuat masyarakat mengalami kerugian.

Setelah tahap pasca panen selesai, biasanya masyarakat meninggalkan dusung untuk beberapa minggu dengan tujuan peremajaan lahan yang telah dilakukan pemanenan. Apabila lahan tersebut dirasa sudah layak untuk diolah kembali, maka dilakukan pembersihan lahan baru.

\section{Simpulan}

Pola pengelolaan agroforestry/dusung yang diterapkan masyarakat Negri Laha yaitu pengelolaan secara mata rumah, pribadi dan kelompok. Pengelolaan dusung secara pribadi yaitu pembagian dusung dari orang tua kepada anak dalam suatu keluarga. Dan masing-masing bertanggung jawab penuh terhadap dusung yang diberikan. Dusung secara mata rumah atau dusung dati yaitu pengelolaan dusung yang mencakup keluarga besar dimana semua keluarga besar yang memiliki hubungan darah memiliki hak yang sama untuk mengelola dusung serta dalam hal pembagian hasil. Pengelolaan dusung secara kelompok yaitu dusug yang dikelola oleh sekelompok orang dalam kelompok tani maupun dusung gereja dimana semua hasil akan diberikan untuk kepentingan gereja maupun kelompok tani dalam suatu desa.

\section{Daftar Pustaka}

Amin dkk. 2016. Jenis Agroforestry dan Orientasi Pemanfaatan Lahan di Desa Simoro Kecamatan Gumbasa Kabupaten Sigi. Jurnal Warta Rimba. Vol 4(1) : 97-104.

BKKBN. 1998. Buku Pegangan untuk Petugas Lapangan Mengenai Reproduksi Sehat. Jakarta : BKKBN

BPS. 2018. Maluku Dalam Angka 2018.

Hernanto, F.2007. Ilmu UsahaTani. Jakarta: Penebar Swadaya.

Latue, A. Y., Pattinama, M. J., Lawalata, M. 2019. Sistem Pengelolaan Agroforestry Di Negeri Riring Kecamatan Taniwel Kabupaten Seram Bagian Barat. AGRILAN :Jurnal Agribisnis Kepulauan. 6(3): 212-230. 
Nursalam. 2003. Konsep dan Penerapan Metedologi Penelitian Ilmu Keperawatan Pedoman Skripsi, Tesis dan Instrumen Penelitian Keperawatan. Jakarta: Salemba Medika.

Oszaer, R. 1996. Sistem Agroferstry. Makalah di Sampingkan pada Lokakarya Wanita dalam Sains dan Teknologi Universitas Pattimura Ambon.

Pattinama, M. J. 2014. Resource Potential Of Sanake Fruit (Salac cazalac cavar Amboinensis) And Canary (Canriu Amboinensis) In The Life Of Seram Island Society Moluccas, $<$ http://maxmjpattinama.org/2014/06/resource-potential-of-seram-islandsociety-moluccas/>Diakses 24Juni 2020.

Sedarmayanti, 2003. Good governance: dalam rangka otonomi daerah upaya membangun organisasi efektif dan efisien melalui rekstruriasi dan pemberdayaan. Mandarmaju, Bandung.

Wattimena, G. A. Dan Papilaya E. 2005. Sistem Agroforestry di Maluku. Jurnal Agroforestry. 8(4):245.

Wattimena, J. J., Pattinama, M. J., Sopamena, J.F. 2018. Nilai Sosial Ekonomi Dusung di Negri Porto Kecamatan Saparua Kabupaten Maluku Tengah. AGRILAN :Jurnal Agribisnis Kepulauan. 6(2):155-170 